\title{
Conversion of 1,2,5-Selenadiazoloporphyrazine to Diformamidoporphyrazine
}

\author{
Anwar Ul-Haq and Pavel A. Stuzhin ${ }^{\circledR}$ \\ Department of Organic Chemistry, Ivanovo State University of Chemical Technology, RF-153000 Ivanovo, Russia \\ ${ }^{\circledR}$ Corresponding author E-mail: stuzhin@isuct.ru
}

\begin{abstract}
Attempt to obtain imidazoporphyrazine by treatment of formic acid on "diaminoporphyrazine" formed in situ by deselenation of hexaphenyl substituted (1,2,5-selenadiazolo)porphyrazine in the presence of $\mathrm{H}_{2} \mathrm{~S}$ and pyridine unexpectedly led to diformamidoporphyrazine. It is suggested that formation of imidazoporphyrazine is hindered by steric strain appearing in the case when two 5-membered heterocycles-pyrrole and imidazole are fused together.
\end{abstract}

\section{Introduction}

It is known that reductive opening of the 1,2,5selenadiazole ring leads to the vicinal diaminospecies ${ }^{[1]}$ and $\mathrm{H}_{2} \mathrm{~S}$ has been reported ${ }^{[2,3]}$ as a convenient reducing agent. This reaction has been used for the peripheral modification of porphyrazines with annulated 1,2,5-selenadiazole rings. ${ }^{[4-6]}$ In a common procedure $\mathrm{H}_{2} \mathrm{~S}$ was bubbled through the pyridine solution of 1,2,5-selenadiazoloporphyrazines until the characteristic colour change and following treatment of the reaction mixture with $\alpha$-diketones led to pyrazinoporphyrazines. ${ }^{[4,5]}$ When aromatic aldehydes were used the Schiff-base porphyrazines were obtained. ${ }^{[6]}$ The in situ formation of the intermediate vicinal aminoporphyrazine species was postulated. Recently investigating the reaction products obtained by treatment of the $\mathrm{Fe}^{\mathrm{II}}$ complex of hexaphenyl substituted 1,2,5selenadiazoloporphyrazine $\left[\mathrm{Py}_{2} \mathrm{Fe}^{\mathrm{II}}\left\{\mathrm{SeN}_{2}\right\} \mathrm{PAPh}_{6}\right]$ with $\mathrm{H}_{2} \mathrm{~S}$ in chloroform in the presence of $1-2 \%$ pyridine we have observed the direct substitution of Se atom by S atom with formation of the 1,2,5-thiadiazole analogue $\left[\mathrm{Py}_{2} \mathrm{Fe}^{\mathrm{II}}\left\{\mathrm{SN}_{2}\right\} \mathrm{PAPh}_{6}\right] .^{[7]}$ According to the mass-spectral and UV-vis data under these reaction conditions the annulated $1,2,5$-selenadiazole ring is first converted to the S,Se-
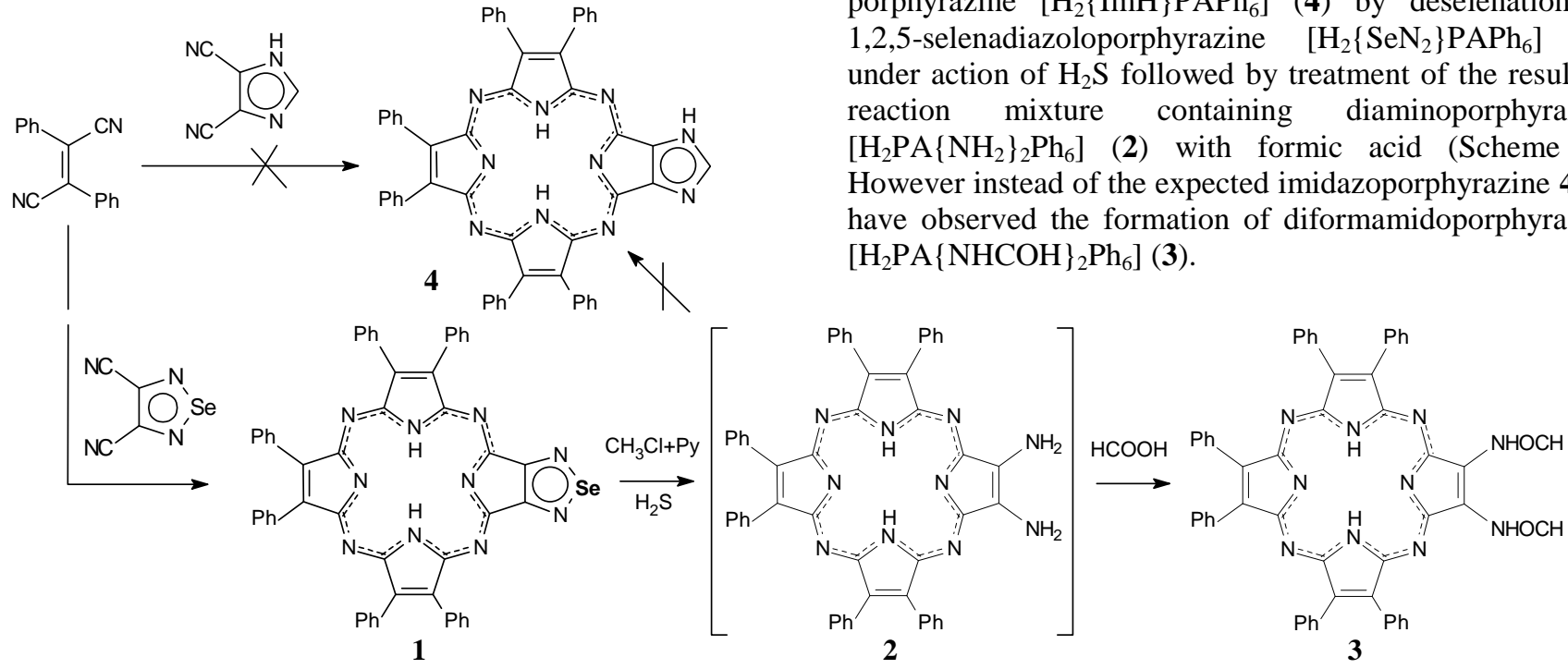

Scheme 1. bridged 6- or 7-membered heterocycle which can be either aromatized with expulsion of $\mathrm{Se}$ and excessive $\mathrm{S}$ atoms to 1,2,5-thiadiazoloporphyrazine or further reduced to vicinal diaminoporphyrazine. Due to instability of N-S and N-Se bonds in the intermediate S,Se-substituted diazine and diazepine species in acidic media, they should give similar products in reaction with electrophiles, e.g. with carbonyl compounds, as vicinal diaminoporphyrazine. It was attractive to use these reactive species for peripheral modification of porphyrazines.

Aromatic ortho-diamines react readily with carboxylic acids, e.g. with formic acid, with formation of imidazo derivatives. Thus, 4,5-diaminophthalodinitrile reacted with $\mathrm{RCOOH}(\mathrm{R}=\mathrm{H}, \mathrm{Me}, \mathrm{Pr})$ to give 5,6-dicyanobenzimidazoles which were then converted to tetra(5,6-benzimidazo)porphyrazines by usual template condensation procedure in the presence of metal salts. ${ }^{[8,9]}$ However, commercially available 4,5-dicyanoimidazole failed to form corresponding tetra(imidazo)porphyrazine in analogous template tetramerization procedure ${ }^{[10]}$ It was reported that only its Nalkylated derivatives can react in mixed co-condensation with substituted phthalodinitriles affording low symmetry (N-alkylimidazo)tribenzoporphyrazines. ${ }^{[11]}$ In present work we have made an attempt to obtain imidazo annulated porphyrazine $\left[\mathrm{H}_{2}\{\mathrm{ImH}\} \mathrm{PAPh}_{6}\right]$ (4) by deselenation of 1,2,5-selenadiazoloporphyrazine $\quad\left[\mathrm{H}_{2}\left\{\mathrm{SeN}_{2}\right\} \mathrm{PAPh}_{6}\right] \quad$ (1) under action of $\mathrm{H}_{2} \mathrm{~S}$ followed by treatment of the resulting reaction mixture containing diaminoporphyrazine $\left[\mathrm{H}_{2} \mathrm{PA}\left\{\mathrm{NH}_{2}\right\}_{2} \mathrm{Ph}_{6}\right]$ (2) with formic acid (Scheme 1). However instead of the expected imidazoporphyrazine 4 we have observed the formation of diformamidoporphyrazine $\left[\mathrm{H}_{2} \mathrm{PA}\{\mathrm{NHCOH}\}_{2} \mathrm{Ph}_{6}\right](3)$. 


\section{Experimental}

UV-vis spectra were recorded using Hitachi U-2000 spectrophotometer. MALDI-TOF spectra were measured on Ultraflex Brucker Daltonics mass-spectrometer without matrix or with CCA matrix.

Reagents and solvents for synthesis, chromatography and spectroscopic characterization of compounds were pure chemicals (Fluka, Aldrich). 4,5-Dicyanoimidazole was prepared following the known procedure ${ }^{[12]}$ and was identical with the commercial product (Aldrich). 7,8,12,13,17,18-Hexaphenyl[1,2,5]selenadiazolo[3,4-b]porphyrazine, $\left[\mathrm{H}_{2}\left\{\mathrm{SeN}_{2}\right\} \mathrm{PAPh}_{6}\right]$ (1) was prepared as described in our recent works. ${ }^{[7,13]}$

2,3-Diformamido-7,8,12,13,17,18-hexaphenylporphyrazine, $\left[\mathrm{H}_{2} \mathrm{PA}\left\{\mathrm{NHCOH}_{2} \mathrm{Ph}_{6}\right](\mathbf{3}): \mathrm{H}_{2} \mathrm{~S}\right.$ was bubbled through solution of $\left[\mathrm{H}_{2}\left\{\mathrm{SeN}_{2}\right\} \mathrm{PAPh}_{6}\right]$ (1) (20 mg, $\left.0.023 \mathrm{mmol}\right)$ in pyridinechloroform mixture $(1: 4,5 \mathrm{ml})$ for 1 min until colour was changed from green to dark blue. Then formic acid $(20 \mathrm{ml})$ was added and solution was refluxed for 1 hour. After vacuum distillation of solvents residue was dissolved in chloroform and chromatographed on silica gel. The first fraction was collected and after evaporation of the solvent $15.7 \mathrm{mg}(81 \%)$ of $\mathbf{3}$ was obtained.

MS (MALDI-TOF): $\mathrm{m} / \mathrm{z}=858(100 \%)[\mathrm{M}+\mathrm{H}]^{+}$, calc $\mathrm{m} / \mathrm{z}=$ 857. UV-vis $\lambda_{\max }\left(\mathrm{CHCl}_{3}\right) \mathrm{nm}\left(A / A_{\max }\right): 361(1.00), 448(0.51)$, $589(0.51), 671(0.88)$.

\section{Results and Discussions}

We have attempted to prepare imidazoporphyrazine $\left[\mathrm{H}_{2}\{\mathrm{ImH}\} \mathrm{PAPh}_{6}\right](4)$ using two approaches - (i) by direct synthesis from two dinitrile precursors and (ii) by peripheral modification of porphyrazine macrocycle.

Mixed co-cyclotetramerization (i) of diphenylfumarodinitrile taken in excess with 4,5-dicyanoimidazole (4:1 molar ratio) in the presence of $\mathrm{Mg}^{\mathrm{II}}$ butoxide in $n$-butanol under reflux led exclusively to $\mathrm{Mg}^{\mathrm{II}}$ complex of symmetrical octaphenylporphyrazine $\left[\mathrm{MgPAPh}_{8}\right]$ and no formation of $\mathbf{4}$ or other low-symmetry imidazo-annulated porphyrazines was observed. This is in contrast with successful use of this procedure for preparation of $\mathrm{Mg}^{\text {II }}$ complexes of 1,2,5-thiadiazolo-, 1,2,5-selenadiazolo- and benzoannulated $\beta$-phenylsubstituted porphyrazines from diphenylfumarodinitrile and corresponding heterocyclic dinitrile or phthalodinitrile. ${ }^{[7,13]}$

For peripheral modification (ii) we have chosen $\left[\mathrm{H}_{2}\left\{\mathrm{SeN}_{2}\right\} \mathrm{PAPh}_{6}\right]$ (1) and studied first its behaviour in the presence of $\mathrm{H}_{2} \mathrm{~S}$. Bubbling of $\mathrm{H}_{2} \mathrm{~S}$ into the solution of $\left[\mathrm{H}_{2}\left\{\mathrm{SeN}_{2}\right\} \mathrm{PAPh}_{6}\right]$ (1) in pure chloroform did not produce any changes in the UV-vis spectra. However, in the presence of pyridine additions (10-20\%) the colour of the solution saturated with $\mathrm{H}_{2} \mathrm{~S}$ was rapidly changed from green to dark blue. In the UV-vis spectra two characteristic $Q$ bands (576 and $694 \mathrm{~nm})$ of the initial 1,2,5selenadiazoloporphyrazine $\mathbf{1}$ disappeared and the broad absorption band with maximum at $578 \mathrm{~nm}$ appeared (Figure 1 , spectra $a$ and $b$ ). Such broad $Q$-band is characteristic feature of the UV-vis spectra of aminosubstituted porphyrazines. ${ }^{[14]}$ In the MALDI-TOF spectra of the reaction probe the peak corresponding to the molecular ion $[\mathrm{M}+\mathrm{H}]^{+}$of diaminoporphyrazine $\left[\mathrm{H}_{2} \mathrm{PA}\left\{\mathrm{NH}_{2}\right\}_{2} \mathrm{Ph}_{6}\right]$ (2) was observed at $m / z=801$. The mass-spectrum contains also the peak at $\mathrm{m} / z=827$ which can be assigned to $1,2,5-$ thiadiazoloporphyrazine $\left[\mathrm{H}_{2}\left\{\mathrm{SN}_{2}\right\} \mathrm{PAPh}_{6}\right]$. However, in the UV-vis spectrum of the reaction mixture no indication

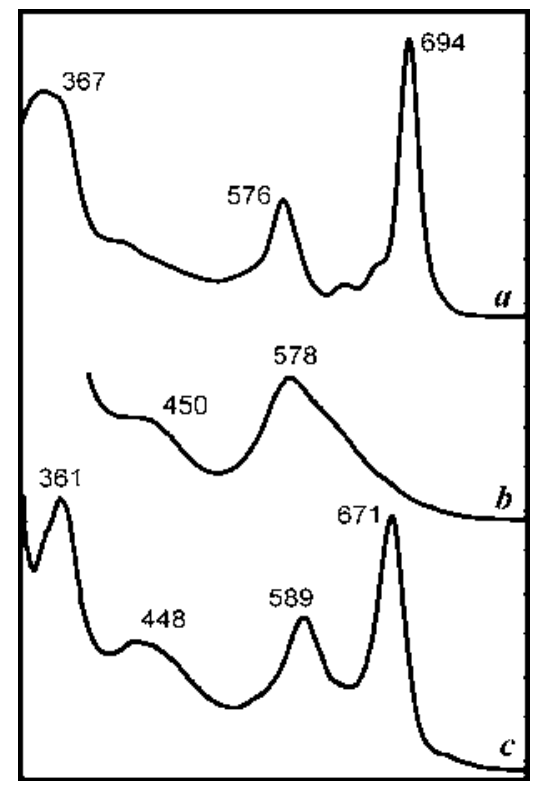

Figure 1. UV-vis spectra of $\mathbf{1}(a), \mathbf{2}(b)$ and $\mathbf{3}(c)$ in chloroform.

can be seen about presence of $\left[\mathrm{H}_{2}\left\{\mathrm{SN}_{2}\right\} \mathrm{PAPh}_{6}\right]$ which have $Q$-bands at 574 and $679 \mathrm{~nm}^{[13]}$ Taking into account previous observations made for the $\mathrm{Fe}^{\mathrm{II}}$ complex $\left[\mathrm{Py}_{2} \mathrm{Fe}^{\mathrm{II}}\left\{\mathrm{SeN}_{2}\right\} \mathrm{PAPh}_{6}\right],{ }^{[7]}$ we can conclude that also in the case of the free base $\left[\mathrm{H}_{2}\left\{\mathrm{SeN}_{2}\right\} \mathrm{PAPh}_{6}\right]$ the reaction mixture after treatment with $\mathrm{H}_{2} \mathrm{~S}$ contains along with diaminoporphyrazine $\left[\mathrm{H}_{2} \mathrm{PA}\left\{\mathrm{NH}_{2}\right\}_{2} \mathrm{Ph}_{6}\right]$ (2) some amount of its precursors with the $\mathrm{S}, \mathrm{Se}$-substituted diazine and diazepine rings $\left.\left[\mathrm{H}_{2}\left\{(\mathrm{NH})_{2} \mathrm{X}\right)\right\} \mathrm{PAPh}_{6}\right]\left(\mathrm{X}=\mathrm{SSe}, \mathrm{S}_{2}, \mathrm{~S}_{3}\right)$. One can suppose that upon evaporation of the solvent before and/or during mass-spectral measurements these species are transformed to the more stable 1,2,5-thiadiazole derivative $\left[\mathrm{H}_{2}\left\{\mathrm{SN}_{2}\right\} \mathrm{PAPh}_{6}\right]$.

We have tried to convert $\left[\mathrm{H}_{2} \mathrm{PA}\left\{\mathrm{NH}_{2}\right\}_{2} \mathrm{Ph}_{6}\right](2)$ and its precursors $\left.\left[\mathrm{H}_{2}\left\{(\mathrm{NH})_{2} \mathrm{X}\right)\right\} \mathrm{PAPh}_{6}\right]\left(\mathrm{X}=\mathrm{SSe}, \mathrm{S}_{2}, \mathrm{~S}_{3}\right)$ into imidazaporphyrazine $\left[\mathrm{H}_{2}\{\mathrm{ImH}\} \mathrm{PAPh}_{6}\right](4)$ by treatment of the reaction mixture with formic acid. The UV-vis spectrum of the reaction product obtained after chromatography is shown in Figure $1(c)$. It contains two narrow $Q$-bands in the visible region which is typical for porphyrazine having $C_{2 \mathrm{v}}$ symmetry of the $\pi$-chromophore. The maxima of the long-wave $Q_{1}$-component is shifted hypsochromically and $Q_{2}$-component bathochromically and the splitting of the $Q$ band is reduced from $2950 \mathrm{~cm}^{-1}$ to $2075 \mathrm{~cm}^{-1}$ as compared with the initial $\left[\mathrm{H}_{2}\left\{\mathrm{SeN}_{2}\right\} \mathrm{PAPh}_{6}\right]$. Such spectrum might be characteristic for imidazoporphyrazine 4 . However in the MALDI-TOF mass-spectrum of this species (Figure 2) no peak which can be assigned to the molecular ion of imidazo derivative $\left[\mathrm{H}_{2}\{\mathrm{ImH}\} \mathrm{PAPh}_{6}\right]$ (calculated $m / z=811$ for $\left[\mathrm{M}^{+}\right]$) is present. Instead the spectrum contains the intense peak at $m / z=858$ which shows no defragmentation but is accompanied by two less intense peaks at 1061 and 1264 having the difference of 203 mass units. The presence of these peaks evidences that under the used reaction conditions formic acid is not condensed with two vicinal amino groups of $\left[\mathrm{H}_{2} \mathrm{PA}\left(\mathrm{NH}_{2}\right)_{2} \mathrm{Ph}_{6}\right]$ (2) with closure of imidazole ring, but formylate them with formation of diformamidoporphyrazine (3). The peak at $\mathrm{m} / \mathrm{z}=858$ corresponds to $[\mathrm{M}+\mathrm{H}]^{+}$and at 1061 and 1264 to the daughter ions $[\mathrm{M}+\mathrm{H}+203]^{+}$and $[\mathrm{M}+\mathrm{H}+2 \cdot 203]^{+}$. 


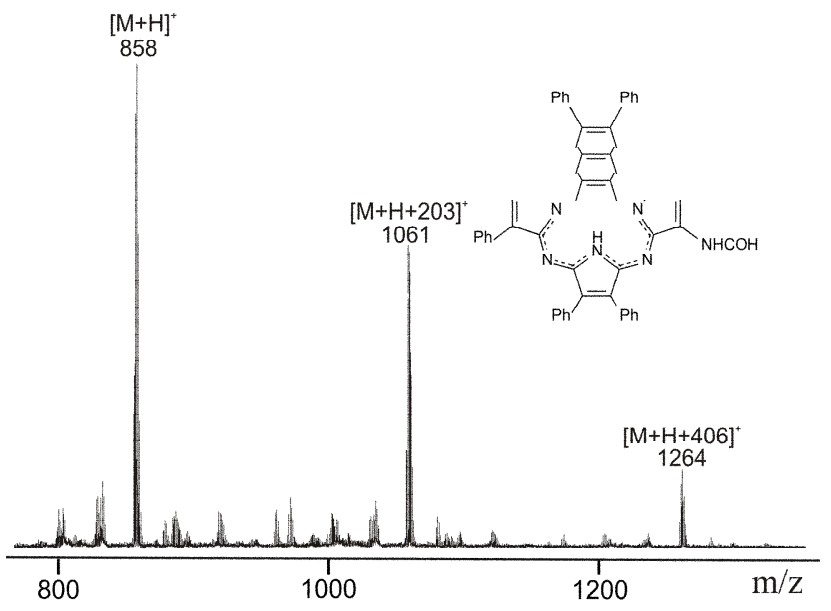

Figure 2. MALDI-TOF mass spectrum of $\mathbf{3}$.

Unsuccessful efforts of synthesis of imidazoporphyrazine both by direct template cyclotetramerization of two dinitrile precursors and by peripheral modification of vicinal diaminoporphyrazine can be understood if one takes into account that in both cases formation of imidazoporphyrazine involves closure of 5-membered ring fused to another 5-membered ring (pyrrole to imidazole or imidazole to pyrrole). According to results of AM1 molecular modelling in the case of fusion of two 5membered rings in the imidazo[4,5- $b$ ]pyrrole fragment the external angle at fused $\mathrm{C}_{\beta}$ atoms $\angle \mathrm{C}_{\alpha} \mathrm{C}_{\beta} \mathrm{N}\left(142-146^{\circ}\right)$ is larger than in the systems with fused 5- and 6-membered rings. Thus in the pyrazino[2,3-b]pyrrole fragments in pyrazinoporphyrazines $\angle \mathrm{C}_{\alpha} \mathrm{C}_{\beta} \mathrm{N}$ is $130-131^{\circ}$ and in the isoindole fragments of phthalocyanines $\angle \mathrm{C}_{\alpha} \mathrm{C}_{\beta} \mathrm{C}$ is 131$132^{\circ}$. In the case of 1,2,5-thia(selena)diazoloporphyrazines, where also two 5-membered rings are also annulated to one another, the presence of large $\mathrm{S}$, Se atoms decreases the value of $\angle \mathrm{C}_{\alpha} \mathrm{C}_{\beta} \mathrm{N}$ to $139-141^{\circ}$ making the structure less strained. It is noteworthy, that porphyrazines with annulated 5 -membered heterocycles consisting of only the $2 p$ elements $(\mathrm{C}, \mathrm{N}, \mathrm{O})$ are practically unknown. ${ }^{[10]}$ Evidently formation of the system with two fused 5-member rings, when possible, requires more severe conditions than that

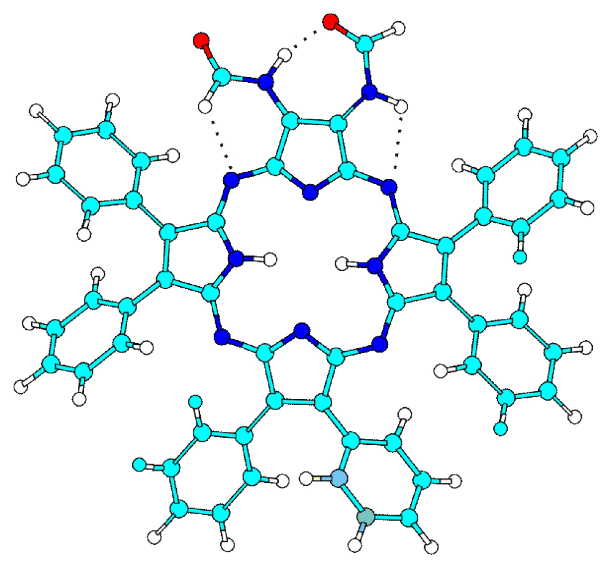

Figure 3. The AM1 optimized structure of $\mathbf{3}$. used in our experiments. In our case since the closure of the imidazole ring was hindered by steric strain, formylation of vicinal amino groups has occurred. Semiempirical AM1 calculations demonstrate that the obtained structure of bisformamide derivative $\mathbf{3}$ can be additionally stabilized by formation of hydrogen bonds, and formylamino groups adopt conformation which is close to planarity (Figure 3). This enables their conjugation with porphyrazine chromophore and agrees with the character of UV-vis spectra.

\section{Conclusion}

In summary, we have investigated the reaction of deselenation of 1,2,5-selenadiazoloporphyrazine and reaction of intermediate "diaminoporphyrazines" with formic acid. The closure of imidazole ring is hindered by steric strain and did not occur under condition used. Instead new diformamidoporphyrazine was obtained and characterized by mass-spectrometry and UV-vis data.

Acknowledgements. This work have received the partial financial support from Russian Foundation of Basic Research (Grant No 06-03-81022).

\section{References}

1. Pesin V.G. Usp. Khim. 1970, 39, 1950. (Russ. Chem. Rev. 1970, 39, 923).

2. (a) Bertini V., De Munno A. Chim. Ind. 1967, 49, 874; (b) Bertini V. Gazz. Chim. Ital. 1967, 97, 1870.

3. Begland R.W. US Patent 3849494, 1974.

4. Bauer E.M., Ercolani C., Galli P., Popkova I.A., Stuzhin P.A. J. Porphyrins Phthalocyanines 1999, 3, 371-379.

5. Baum S.M., Trabanco A.A., Montalban A.G., Micallef A.S., Zhong C., Meunier H.G., Suhling K., Phillips D., White A.J.P., Williams D.J., Barrett A.G.M., Hoffman B.M J. Org. Chem. 2003, 68, 1665-1670.

6. (a) Zhao M., Stern C., Barrett A.G.M., Hoffman B.M. Angew. Chem., Int. Ed. 2003, 42, 462-465; (b) Zhao M., Zhong C., Stern C., Barrett A.G.M., Hoffman B.M. Inorg. Chem. 2004, 43, 3377-3385.

7. Ul-Haq A., Donzello M.P., Stuzhin P.A. Mendeleev Commun. 2007, 17, 337-339.

8. Kudrik E.V., Shaposhnikov G.P. Mendeleev Commun. 1999, 85-86.

9. Kudrik E.V., Shaposhnikov G.P., Balakirev A.E. Zh. Obshch. Khim. 1999, 69, 1372-1376. (Russ.).

10. Stuzhin P.A., Ercolani C. Porphyrazines with Annulated Heterocycles, in The Porphyrin Handbook (Kadish K.M., Smith K.M., Guilard R., Eds), Amsterdam, Academic Press, 2003, 15, 263-364.

11. Bakboord J.V., Cook M.J., Hamuryudan E. J. Porphyrins Phthalocyanines 2000, 4, 510-517.

12. Woodward D.W. US Patent 2534331, 1949.

13. Stuzhin P.A., Pimkov I.V., Ul'-Khak A., Ivanova S.S., Popkova I.A., Volkovich D.I., Kuz'mitskii V.A., Donzello M.P., Russ. J. Org. Chem. 2007, 43, 1854-1863.

14. Montalban A.G., Jarrell W., Riguet E. McCubbin Q.J., Anderson M.E., White A.J.P., Williams D.J., Barrett A.G.M., Hoffman B.M. J. Org. Chem. 2000, 65, 2472-2478. 